\section{Powerful mythology}

David W. Pearce

The Price of Nuclear Power.

By Colin Sweet.

Heinemann Educational: 1983. Pp.107.

Pbk $£ 3.95$.

IN THE space of only five years the focus of public argument about nuclear power in the United Kingdom has shifted from the all-embracing issues of social cost - accidents, routine radiation, civil liberties, proliferation and the "distance" of decision-making from the voting public to economic cost comparisons. The 1977 Windscale Inquiry into the construction of a further fuel reprocessing plant established that all the social arguments were at least on the agenda. The 1983 Sizewell Inquiry into the construction of a pressurized water reactor is hearing a great deal about the unit costs of nuclear as opposed to coalfired power stations. The shift in emphasis is partly because Windscale was concerned with one aspect of the fuel cycle, reprocessing, which has international dimensions. Sizewell is concerned with one new power station, although to make any sense at all it must be the test case for a series-ordering of PWRs on a limited scale over the next decade or so. But much of the change reflects more of a holding operation on the part of the nuclear opposition: the socialcost arguments may not have been entirely won but they have become legitimate. It remains to knock the purely economic costings on the head and, intellectually, anyway, nuclear power would be finished.

Colin Sweet's book is written in this context and it has quite clearly been designed to coincide with the Sizewell hearings, so much so that readers unfamiliar with nuclear arguments in the UK will find it oblique in its institutional references. It is also meant to be part of the culmination of a sustained effort in the past five years to get the economics sorted out. To this end, reports by the House of Commons Select Committee on Energy, the Monopolies and Mergers Commission, reflective views of the independent economists and the pressure applied by the committed lobbies have led to a situation in which a full reappraisal of nuclear power economics should be possible. Alas, while openly written from the anti-nuclear standpoint, Sweet's book does not offer that reappraisal and manages to extend and confuse some of the mythology into the bargain.

Sweet's thesis is, first, that the role which nuclear power can play in the energy future is limited to base load electricity which is unlikely to include space heating. This is because consumers do not reveal a preference for substituting electricity for gas or even oil, and because, anyway, the level of overall energy demand has been greatly exaggerated by the forecasters. Second, nuclear power is not cheaper than coal-fired electricity and can only be made to appear so by fudging the books. Notably, what is required is a fully fledged current cost-accounting framework in which investment appraisals, plant by plant, are presented using established appraisal techniques. Third, the chances of demonstrating this last set of propositions are small because of the secrecy surrounding nuclear power, a secrecy resorted to so that committed views on the part of the "pro-nuclear lobby" are not to be revealed as self-delusion.

Sweet is on happiest ground when talking about nuclear versus coal costings (Chapter 5). Even here, however, one would wish for full notes on the sources of data. On the general energy policy context, and in invoking the discipline of economics, he is distinctly uncomfortable and discomforting as a researcher. The problems range from simple mistakes to the setting up of innumerable straw men. Thus Sweet declares that the absolute contribution to electricity output by nuclear power declined from 1971 to 1981 . It rose from 19.5 TWh to $23.4 \mathrm{TWh}$, as his own data show. He declares that total primary energy demand fell by 20 million tonnes oil equivalent over the same period "and continues to fall", an answer one can only get by careful selection of the base year given that energy consumption rose to 1973 , fell to 1975 , rose to 1979 and fell in the two years following. These would be quibbles in a short review but for Sweet's conclusion that the Central Electricity Generating Board's case "seems to be somewhat weak" given the context of falling overall demand.

The straw man phenomenon occurs frequently. Because Sir Martin Ryle calculated that nuclear generating capacity would have to rise from 56 gigawatts to a startling 230 gigawatts if all fossil fuels were displaced, this is somehow meant to persuade us of the Gargantuan silliness of nuclear claims. But not only would no nuclear enthusiast claim as much, but the quotation of Ryle's computation flatly contradicts Sweet's own very sensible point that electricity of any kind has a limited role in energy substitution in the UK. Much the same disappointment extends to the old chestnut of the Atomic Energy Authority's "programme" in evidence to the Royal Commission on Environmental Pollution in 1976. The AEA is not responsible for forecasts in the UK, nor does it buy generating equipment. Sweet manages to present all of this highly misleading material without once printing the actual official projections of energy demand in the UK. The other errors are manifold, from confusion between rates of return and rates of discount to defining an energy ratio (energy per unit of national output) in terms that can only mean Sweet is thinking of an energy elasticity (percentage changes in energy divided by percentage changes in output) whilst consulting data about the former.
The lesson in all this is that we must surely accept the fragility of the relationship between pro- and anti-nuclear power lobbies and, while replete with conspiracy theory, Colin Sweet's book is mercifully clear of the vocabulary-abuse common to both sides. But if Sweet's book is intended as a further nail in what he sees as the coffin of nuclear power he has hammered neither straight nor true. The debate deserves better, especially as those qualified to assess the economics of nuclear power in the sphere of disinterested research are few and far between.

David Pearce, currently Professor of Political Economy at the University of Aberdeen, is due to become Professor of Political Economy at University College London in October 1983. He is senior author of Decision Making for Energy Futures (Macmillan, 1979).

\section{Learning from Seveso}

Frederick Warner

The Chemical Scythe: Lessons of 2,4, 5-T and Dioxin.

By Alastair Hay.

Plenum: 1982. Pp.264. \$??, £??

The Chemical Scythe, the first in a series of books to be published by the International Disaster Institute, deals principally with the "lessons of 2,4,5-T and dioxin". The author, Dr Alastair Hay, has written widely on the Seveso accident. He has now cast his net more widely to examine different incidents involving 2,4,5-T plus dioxin and others in which chlorinated hydrocarbons, such as hexachlorophene, were the toxic agent. This leads him to discussions of the effect of 2,4,5-T used as a defoliant in Vietnam, Laos and Cambodia, and to the possible adverse effects from past dumping of chemical residues in places such as Love Canal near Niagara.

All of these issues raise emotions which vary according to the closeness of the observer. To the British, who often complain of isolationist trends in the United States, there is little appreciation of the intense feelings generated by the war in Vietnam and the claims of ex-servicemen that they have suffered long-term damage from chemical insults. The nature and severity of these insults is witnessed by papers from Vietnam which, however, have not stood up to detailed critical scrutiny by such bodies as the National Academy of Sciences. Dr Hay has set out the various arguments from the literature available, and has added the accounts of journalists who have made their own contemporaneous or later investigations. The reader is left to make his own judgement since Hay gives the opposing views without putting any particular emphasis. $\mathrm{He}$ is critical however of the failure of chemical manufacturers to release information in order to help the airing of problems in 
public, and concludes that there is still work to be done before the adverse health effects of specific chemicals can be assessed.

Dr Hay could have gone further. Later works from the International Disaster Institute may indeed do this and take up the general nature of disaster, our reactions and the remedies proposed. Unfortunately it appears that analysis of natural disasters will be excluded although they kill tens and hundreds of thousands in floods, typhoons and earthquakes; man-made disasters are never on this scale unless they arise from the failure of dams or embankments installed to control all but the most exceptional floods.

\section{IMAGE UNAVAILABLE FOR COPYRIGHT REASONS}

Symbol of Seveso - August 10th, 1976, and workmen begin to cleanse the ICMESA plant.

The special disaster for Dr Hay was that at Seveso, in northern Italy, on July 10 1976, where the ICMESA factory of Hoffman-La Roche made trichorophenol, used (but not in this case) to make 2,4,5-T, by hydrolysis of 1,2,4,5-tetrachlorobenzene with caustic soda. The reaction is carried out at atmospheric pressure in ethylene glycol solution which is then distilled under vacuum at a temperature not exceeding $185^{\circ} \mathrm{C}$. The accident happened following an exothermic reaction, probably initiated from a hot-spot after the agitator and the steam were shut off, so that the temperature rose to $240^{\circ} \mathrm{C}$ and the reactor pressure to 3.55 bars, rupturing a disk in a vent-line discharging into the atmosphere. The temperature rise caused the formation of 2,3,7,8-tetrachlorodibenzo- $p$-dioxin, one of the 75 possible isomers of dioxin, having a toxicity to guinea-pigs and mice represented by $\mathrm{LD}_{50}$ values of 2 and $284 \mu \mathrm{g} / \mathrm{kg}$. Hay gives an extended account of the chemistry of dioxins, their formation and destruction by incineration, photolysis, electrochemical oxidation and biodegradation, and estimates the amount of dioxin formed at Seveso to have been $250-500 \mathrm{~g}$. This is considerably lower than the $2 \mathrm{~kg}$ estimated for the Lombardy Regional Council.

The toxicology of dioxin is discussed mainly in relation to animal experiments. The effect on man was shown at Seveso in workers and their families by the rapid development of chloracne, and Hay devotes an entire chapter to this extremely disfiguring disease. The alarming feature of the Seveso discharge was its dispersion over a wide area from the two-phase jet issuing at sonic speed from the vent. Near the source, heavier droplets were caught in vegetation and some animals died after eating it. Further downwind the smaller droplets contaminated houses and fields, the dioxin content causing 187 cases of chloracne in children but none in adults. These cases had all cleared up by 1980 (the gross lesions on the faces of two children given world-wide publicity were due to the sodium trichlorophenate from the reactor).

Dr Hay records in detail the action taken after the accident by Hoffman-La Roche and Italian government, both local and national. The warnings and clear advice from the company were in contrast with the vacillation of the public authorities; the lack of emergency procedures and political confusion made the people of Seveso victims of a social disaster far greater than any physical damage they suffered from the chemical itself. The publicity given to possible teratogenetic effects triggered demands for abortion to be freely available, opposed by the local clergy. Even worse, the agricultural and manufactured products of the area became unsaleable because no firm exculpation came from the authorities. Hay's account shows Dr Reggiani, the medical director of Hoffman-La Roche, acting with the highest integrity throughout the affair. His pursuit in the subsequent years of comparative health statistics for spontaneous abortions, birth defects and many other indicators has shown no detectable differences between the people in the contaminated area and those outside.

At the root of this book is a question how do we remain alert to the detrimental effects of chemicals shown in some animal experiments without denying to the community products whose utility outweighs the risks? Hay shows how many uncertainties exist; for example, dioxin shows no mutagenicity in the Ames test. Yet the Seveso incident has given rise to the Seveso directive of the EEC, and to the campaign in the United Kingdom to ban 2,4,5-T even though there is already a stringent limit on dioxin content.

It is time for more agreement and less debate on how to compare benefits with costs, particularly on the reduction of risk in the use of medicines. In the Royal Society study group on risk, it was argued that action to reduce the risk of one death would justify spending between $£ 100,000$ and $£ 1,000,000$, any more being better spent on other medical benefits. In comparison with the estimated cost of smallpox eradication by the World Health Organization it is arguably too much. That campaign has saved $2,000,000$ lives a year at a cost of $£ 8$ per life. Even more lives could be saved by providing safe drinking water, but the victims are a long way away from Europe and North America. Unlike Seveso and Love Canal, it is hard to make the publicity sensational.

Sir Frederick Warner is a Consulting Chemical Engineer and Visiting Professor at University College London.

\section{States and soldiers}

\section{Richard Langhorne}

\section{The Pursuit of Power: Technology, Armed Force, and Society} since AD 1000.

By William H. McNeill.

Basil Blackwell: 1983. Pp.406. f15.

FEW AGES have been as preoccupied as our own with the preparations for and likely consequences of going to war. Thus The Pursuit of Power, a study of technology, armaments and society as they have developed over a millennium or more, must arouse considerable interest.

The author is William McNeill, an historian who is no stranger to the temptation to seek out and describe patterns of development over very long periods. $\mathrm{He}$ has notably succumbed once already in Plagues and Peoples, his treatment of the incidence of disease published by Blackwell six years ago. Global histories have not been fashionable in recent times, though there are signs - of which this is an example on a comparatively small scale - that we may not be deprived forever of modern successors to Gibbon and Macaulay. Although The Pursuit of Power is not an especially substantial tome, the treatment it offers is far from lightweight. The discussion is tightly packed and marked by great breadth of learning. The conclusions that emerge are often complex, but a finely balanced prose style renders them easily accessible to the general reader.

The pattern perceived by McNeill results from the operation of two factors. First, the diffusion from China during the Sung dynasty (AD 960-1279) of a new kind of economic organization based upon market forces rather than the "command" principle which had characterized the economies of the ancient empires. Secondly, McNeill continues, there was a steady development of ever more efficient weapons, used by increasingly sophisticated armed forces. It was this factor that propelled new economic development. The two effects together came to affect profoundly the creation, structure and behaviour of states. Certainly, it is true that since the evolution of the Italian city states in the fourteenth century, the division of human society into nation states has become a global fact. The more difficult question is whether McNeill's attractively organized explanation for this phenomenon is wholly satisfying.

The ability of economies to generate technological innovation has been a particularly important ingredient of power since the last quarter of the nineteenth century. Economic success, however, and effective military organization have been but two of the ingredients, and it is not certain that a military stimulus has been required on a regular basis to produce successful 